\title{
Designing and testing of a smart firefighting device system (LAHEEB)
}

\author{
Yousef Samkari, Kamel Guedri, Mowffaq Oreijah, Shadi Munshi, Sufyan Azam \\ Department of Mechanical Engineering, Umm Al-Qura University, Saudi Arabia
}

\begin{tabular}{l} 
Article Info \\
\hline Article history: \\
Received Aug 16, 2019 \\
Revised Oct 10, 2019 \\
Accepted Feb 18, 2020 \\
\hline
\end{tabular}

\section{Keywords:}

Extinguishing

Firefighting

Robot

Robotics

Safety

\begin{abstract}
The motivation behind this project is that firefighter's death. Many firefighters are struggling to perform their duty which causes much death while on a mission and the circumstances related to each incident. Firefighters are our heroes and our sense of security in times of trouble. They put themselves on dangerous situations to protect us. At present, the world is moving toward the use of technologies software and hardware. This paper proposed a smart firefighting device system (LAHEEB) which designed to detect the source of fire, extinguish it, and increase the knowledge about fire behavior from incident area. This device can extinguish different types of fire $\mathrm{A}, \mathrm{B}, \mathrm{C}, \mathrm{D}, \mathrm{F} / \mathrm{K}$, electric and metal fire without spreading in the shortest time. This device will reduce the risk of injury for firefighters and possible victims and decrease the monetary losses which increase considerably as fire duration increases. LAHEEB device is consists of two parts. The first part is called the mid-cap which presented the body of the device that has most of the components such as sensors, relays, battery, servo motor, liquid tank, push-button, and Arduino. The second part is called the bottom-cap which presented the moving part of the device that has the significant components of LAHEEB such as servo motor, sprayer, and thermal camera. It also makes use of liquid-tank and spray mechanism for extinguishing the fire. The spraying nozzle is mounted on a servo motor to cover maximum area. Liquid-extinguisher is pumped from the main tank to the nose with the help of a pump. The whole system is programmed using an Arduino DUE board which forms the brain of the system.
\end{abstract}

This is an open access article under the $\underline{C C B Y-S A}$ license.

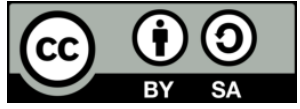

\section{Corresponding Author:}

Yousef Samkari,

Department of Mechanical Engineering,

Umm Al-Qura University,

Al Taif Road, Makkah 24382, Saudi Arabia.

Email: josephsamkari@gmail.com

\section{INTRODUCTION}

Artificial intelligence is a subject that will be useful in many industries, while a robot is a machine that perform tasks usually human do it. The first uses of modern robots were in factories as industrial robots. It is a machine with manufacturing tasks, which allowed production without the need for human assistance [1]. The robots divided into several groups such as tele-robots, telepresence, mobile robots, and autonomous robots [1].

Telerobotic or teleportation is a technical name given to any handled device doing operations controlled by the operator, unlike the robots, the Tele-robots are restricted based on how the operator has a limited range of function and commands compare to the robots. Teleoperation known as telepresence, the human operator, has a sense of being on location so that the experience resembles virtual reality. 
A telepresence robot is similar to a telerobot, and the only difference is providing a data response, such as video and sound. Therefore, telepresence robots commonly used in many fields requiring monitoring procedures, such as child services in nursery and education [2]. The mobile robot is requiring human beings to navigate and carry out tasks [3], while autonomous robots can perform the task independently without the involvement of human beings [4]. Moreover, the industrial robots are multi-function manipulators designed for more specific materials, tools, or devices through numerous programmatic drives to perform several tasks [5]. Many studies and projects have shown that robot can be valuable in medicine [6], rescue operation [7, 8], industry [9] and rehabilitation [10-12].

The use of robots is increasing and become more common today than ever before, and the fire extinguisher robot becomes essential to protect human life. The robot can detect and extinguish a fire by itself [13]. There are many projects related to firefighter robotics have been studied through this project to compare, improve, develop the study of the smart firefighting Device (LAHEEB). The following robots are some examples used to fight a fire in different applications, most of them have advantages and disadvantages that helped to improve this study.

A smart firefighting robot system (LAHHB) [14], this paper provides a detail description of the smart system that help to build the firefighting robot. This robot has many advantages to detect different types of fire and avoid obstacles. Moreover, it helps to put out the source of the fire in a shortest time. From this concept the LAHEEB device is lunched in order to combine all functions with some new features such as a thermal camera to make the device even more accurate and precise in detecting fire and victims in area.

Virtual reality simulation of firefighting robot [15], this system developed in MATLAB/Simulink. It placed for initial testing of control algorithms. This project clearly showed that the robot does not have enough level of functionality, because of low-detailed validation of environment. The robot could operate only in free space without obstacles.

This robot worked as a firefighting robot in houses, and any municipal buildings called Fire protection Robot. In [16] there is a detailed description of using the absolute time firefighting apprentice which moves in an affiliated speed, analyze the blaze, and again extinguish it with the advice of pumping mechanism. The primary system's advantages are detecting fire by complex algorithms, using navigation and using of a sound sensor for activating, while the main disadvantages are a low-efficiency computer, low-power frame, an absence of mapping and return-back.

Firefighting robot [17] is a robot that worked only 15 minutes and then returned to the supply station area. This principle is one of the great applications for firefighting that fit in non-industrial buildings such as houses. The main disadvantages are the little period of working time and low storage of water provided.

Pokey the fire-fighting robot is the robot that listed for coemption and got improved. In [18] there is a detailed description of basic algorithms of operating and the user equipment. The robot equipped with sensors such as a line-sensor, but it does not work very well in a dense smoke area. The advantages of this robot is using of complex firefighting tool and two types of fire sensors. On the other hand, the disadvantages are working in a short distance paced on the sensors range less than $1.5 \mathrm{~m}$, also the absence of optical means of environment perception and low efficiency of the computer.

In this paper, a smart firefighting device (LAHEEB) proposed because firefighters play a significant rule in societies therefore many studies are discussed on the use of device to minimize firefighters' injuries and losses as well as increasing efficiency, safety, and quality of the task and its procedures [19]. The primary function of this device is to detect the source of different types of fire, extinguish it and increase the knowledge about fire behavior from the incident area. There are several existing types of robot for firefighting at home and extinguish forest fires [20]. By using such robots, fire identification and rescue activities can accomplish with higher security and without placing firefighters at high risk and dangerous conditions.

\section{METHODOLOGY}

In this section, the methodology procedures divided into three parts. All parts were assembled to accomplish the function of detecting fire, extinguish it and increase the knowledge about fire behavior. The first part is the mechanicals design structure of the device body. The second part is a hardware implementation of the used parts, while the third is the software design details.

\subsection{Mechanical Design Structure}

SolidWorks software is used to produce a 3D schematic diagram of the bottom-cap of the smart firefighting device (LAHEEB) as shown in Figure 1. Also, it is used to present the mid-cap as shown in Figure 2. The main structure is consisting of two parts: the bottom-cap and the mid-cap. The thickness of the body is $2 \mathrm{~mm}$. The shape of the device is made from aluminum alloy to protect the electronic circuit. 
The surface is smooth and painted. The alloy sheet is resistant to the heat of up to $200{ }^{\circ} \mathrm{C}$ [21]. The body of aluminum contains holes that make it easier to the mounting of flame sensors all around the device to detect fire immediately as shown in Figure 3.

Building the device is going through procedures of building the mid-cap begin with cutting aluminum sheets, pressing them to perform a straight shape, and then attaching them together. Next, building holes to fix flame sensor on them. Then, perform dry putty to prepare the device for the paint. The two caps attached together by servo motor and shaft as shown in the following Figure 3, a design of a complete LAHEEB device using Solidworks with dimensions. The assembly procedures are prepared step by step and tested to make sure everything work and perform correctly. Next, placing the thermal camera, liquid tank, battery, flame sensors, relay, servo motor, and circuit board. After assembling all parts on the device as shown in Figure 4.
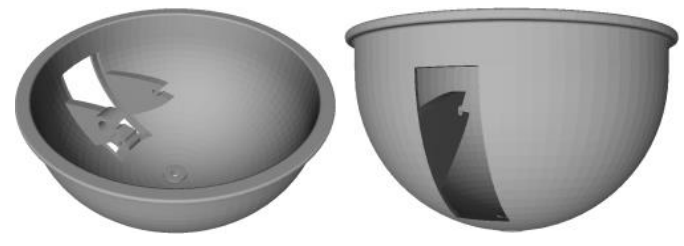

Figure 1. 3D Structure of a bottom-cap of LAHEEB using Solidworks

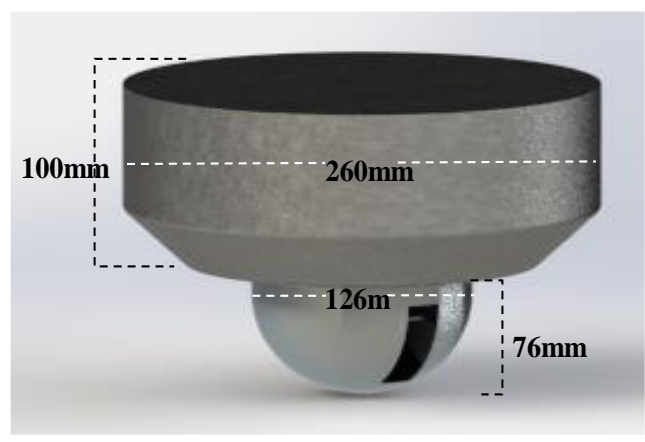

Figure 3. A design of a complete LAHEEB device using Solidworks

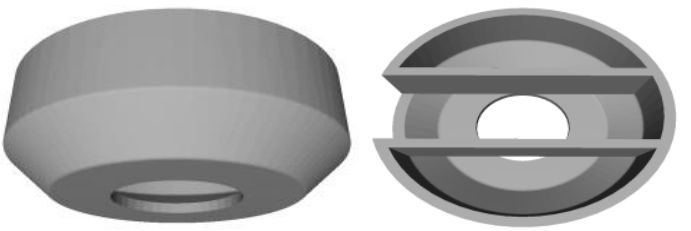

Figure 2. 3D Structure of a mid-cap LAHEEB using SolidWorks

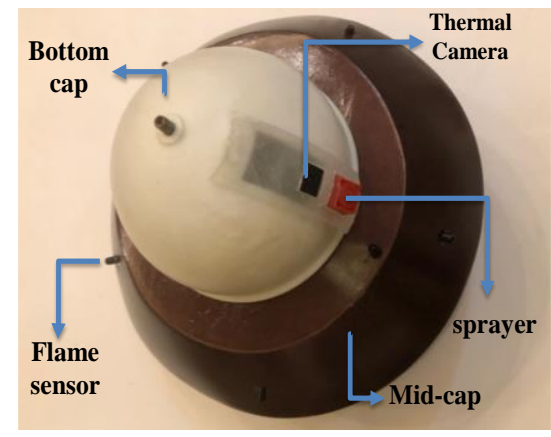

Figure 4. A smart firefighting device system (LAHEEB)

\subsection{Hardware Implementation}

There are several parts of electronics that help in developing LAHEEB such as sensors, microcontroller, DC motors, Motor driver, servo motors and pump. Figure 5 shows the block diagram of LAHEEB process which consists of the input of flame sensor and thermal camera, Arduino DUE as the microcontroller, servo motor and pump as output to move liquid-extinguisher out of the tank.

a. Flame sensors: The flame sensor, as shown in Figure 6, is able to detect a flame by sensing light wavelength between 760 and 1100 nanometers. The distance is range between 20 to $100 \mathrm{~cm}$. The detection angle is 60 degrees [22].

b. Servo motors: Servos are used to operate remote-controlled or radio-controlled toy cars, robots, and airplanes. Servo motors controlled by sending an electrical pulse of variable width or pulse width modulation (PWM), through the control wire [23]. A servo motor has 90 degrees in either direction for a total of 180-degree movement.

c. Fluid Pump: The Fluid pump is a relevant section in this robot as it will pump fire terminate fluid to extinguish the fire immediately no matter what is the class of fire that occurs. The fluid used because it has a proven certificate for extinguishing all types of fire. A very small-size and light-weight pump is the reason for selecting the pump in this project [24]. The working voltage for this pump is around $4 \mathrm{~V}$ to $12 \mathrm{~V}$, and the working current is $1 \mathrm{~A}$.

d. Thermal Camera: The human eye can only see a slight part of the electromagnetic spectrum, so that humans cannot see ultraviolet light and infrared. Thermal imaging, as shown in Figure 7, is used as a valuable diagnostic tool for electrical and mechanical applications [25]. 


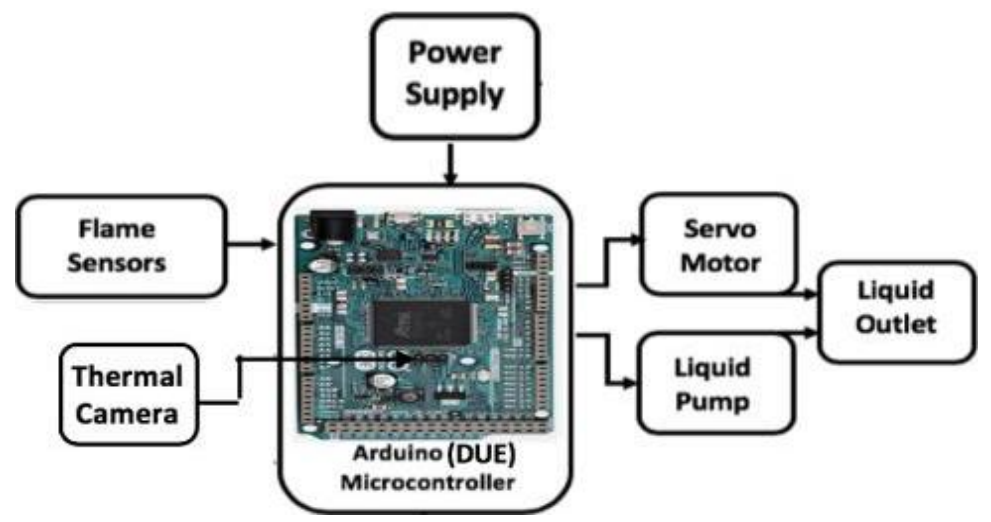

Figure 5. Block Diagram of LAHEEB

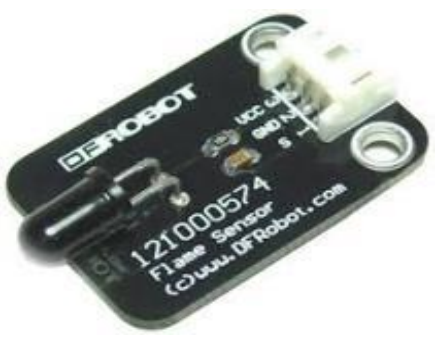

Figure 6. Flame sensor

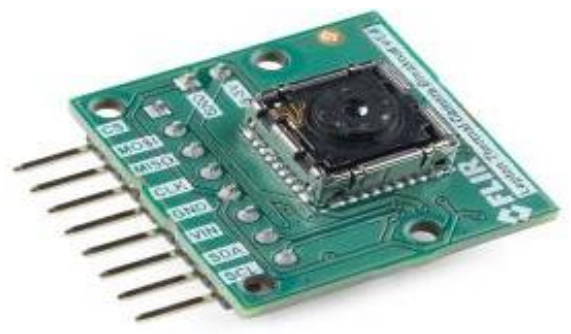

Figure 7. Thermal camera

\subsection{Software design details}

Over the years Arduino has been the brain of many projects, from primary objects to complex scientific instruments $[26,27]$. Arduino DUE used in this project for programming as shown in Figure 8. For programming the microcontrollers, the Arduino provides an integrated development environment (IDE) based on Processing language among with $\mathrm{C}$ and $\mathrm{C}++$ languages. Arduino is used in this project because inexpensive, cross-platform in many operating systems, simple, clear programming environment and it has an open source Arduino IDE which makes it easy to write code and upload it to the board.

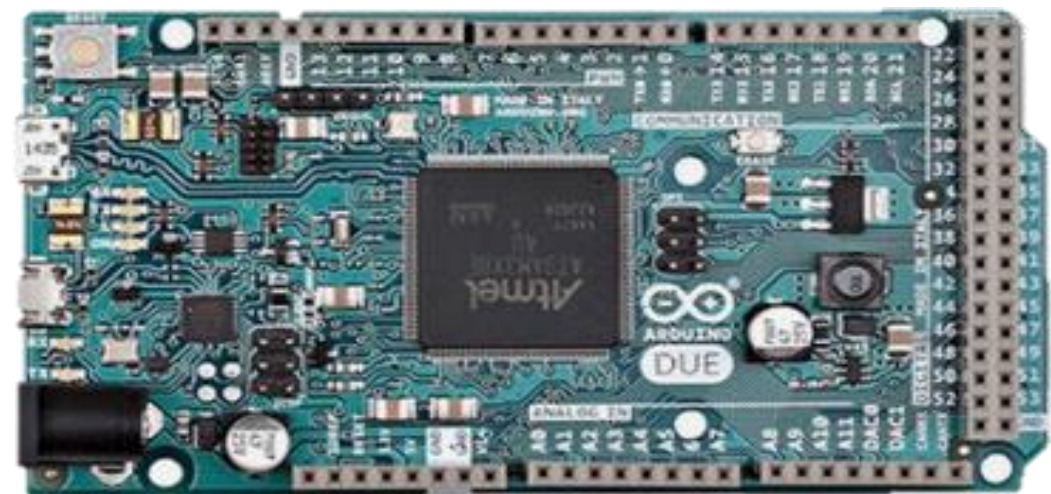

Figure 8. Arduino DUE microcontroller

\section{RESULTS AND DISCUSSION}

A smart firefighting device (LAHEEB) has been developed and successfully can detect the source of fire, extinguish it, and increase the knowledge about fire behavior from incident area. LAHEEB can find the source of fire by using a five-channel flame sensor and ultrasonic sensor. The flame sensor used to detect fire and its location. All sensors are connected to Arduino DUE among with pump and servo motors to control 
the movement of the device in $360^{\circ}$ and $90^{\circ}$ up and down. If the flame sensor detects the fire, the servo motor will stop. The pump will start to react to push the fire terminator fluid in the source of the fire.

Flame and thermal detection are the two types of detection that performed this project. The flame detection test is worked from seven flame sensors that built on LAHEEB device to detect all the range of a room, the test is running by comparing the seven sensors, so the high value is used to move the servo to the position of the that flame and centering the fire source as shown in Figure 9.

Three tests are operated to ensure that the device provide an accurate result, Figures 10 and 11 show the ability of the device to put out the first source of fire, and then moved to the second source of fire and start firefight it. After that, the device also detects the third source of fire and turn the pump on. The figure clearly shows how the bottom-cap turn to the source of fire by using flame and thermal camera. After that, the device checks the source and center the sprayer to pump the fire terminator, Figure 12 show how the device pumps the liquid through sprayer and how the traditional firefighting system does not sense the fire at all.

Thermal Detection is considered one of the most important tests in this device since the camera brings the high resolutions data and an accurate result as well. The idea is to check if the fire is really existing according to flame sensor detection or not. Moreover, it gives a correct location and help to record the situation, so it will help to know what the reason of the fire is. Testing the thermal camera operation runs through Matlab to identify how camera works, and how the information could be useful in the device to detect the source of the fire with its location. Figure 13 shows the Matlab result and how it sees the surfaces of the object, it also shows the source of fire with the human detection as well.

Using this particular thermal camera could help to detect the fire very easily and quickly, Figures 14-16 also some experiments that help to test the quality of the thermal camera. Figures 14-16 show how the camera sees the fire and how the camera sees humans among with the fire. These two experiments not only help to detect the fire but also to detect if there is a victim in the fire area, which will consider a really important information to be send to firefighters.

To sum up, a smart firefighting device system (LAHEEB) can find the source of fire by using seven flame sensors and thermal camera. The flame sensor used to detect fire and its location while thermal used to detect the exact location and make sure there is a fire. The procedure of the device in detecting is described clearly in the flowchart of smart firefighting device (LAHEEB) as shown in Figure 17. All sensors and camera are connected to Arduino DUE among with pump and servo motors to control the movement of the bottom-cap. If any flame sensor detects the fire, the servo motor will go to that location, then thermal camera will check and the pump start pushing the fire terminator fluid in the source of the fire.

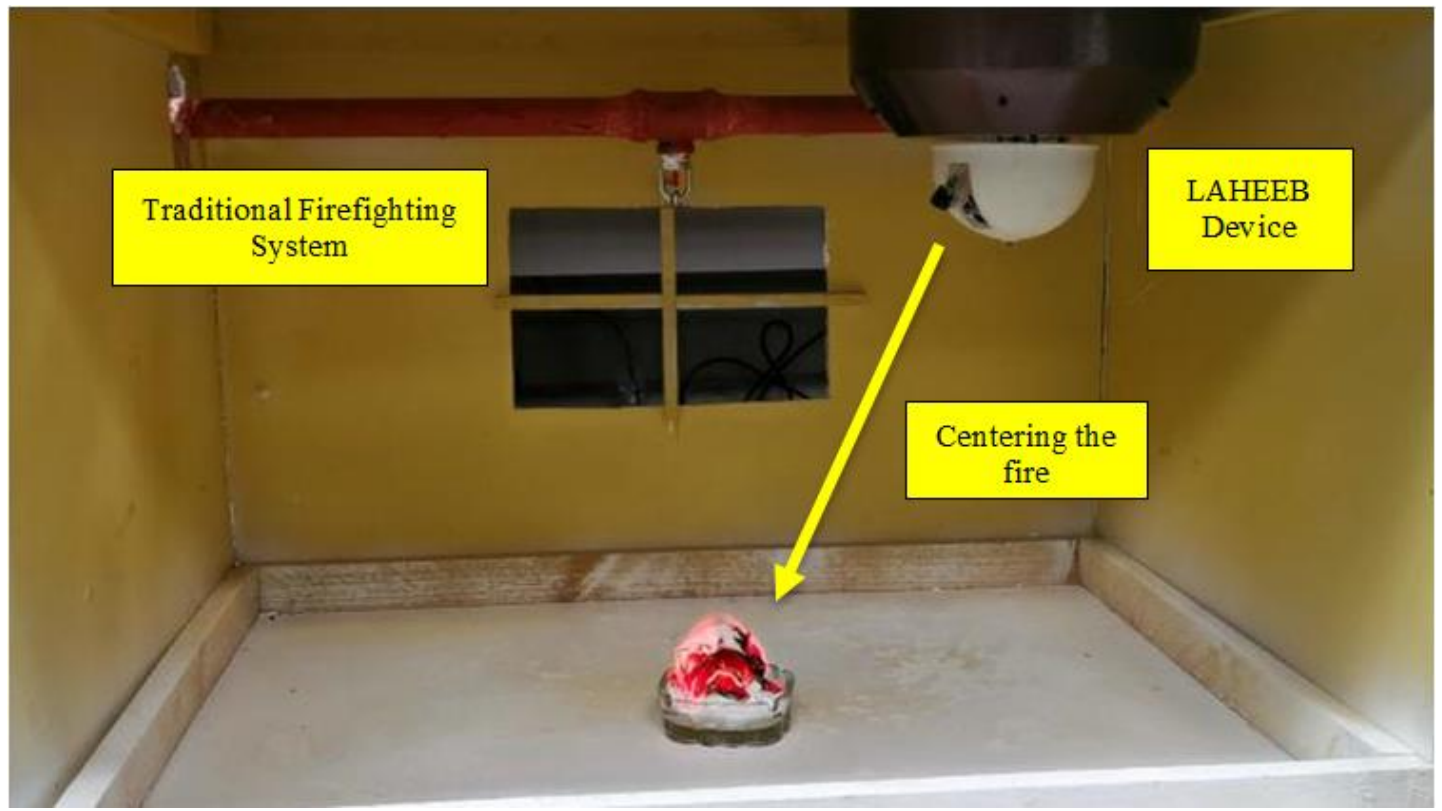

Figure 9. A view of the first test of examine the fire inside the room 


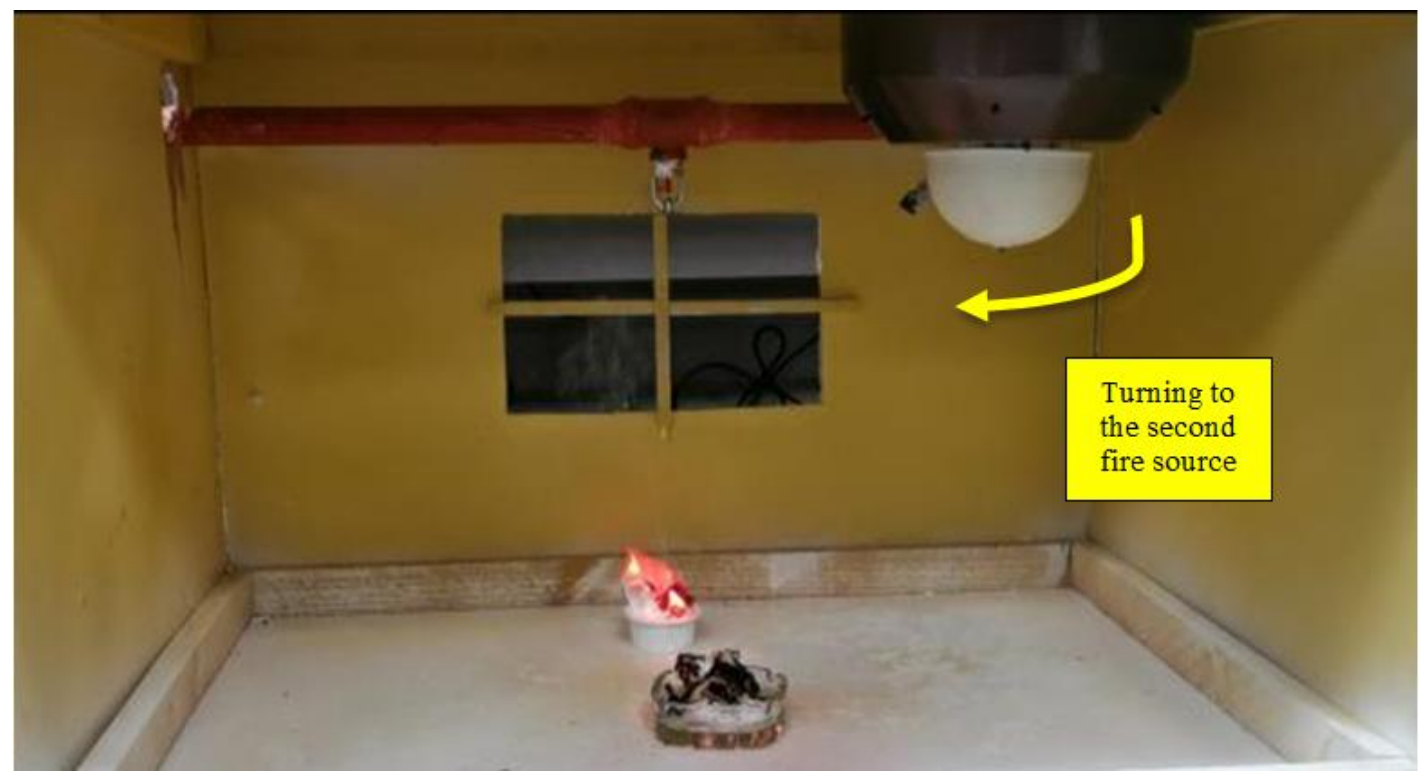

Figure 10. A view of a second examine of the fire inside the room

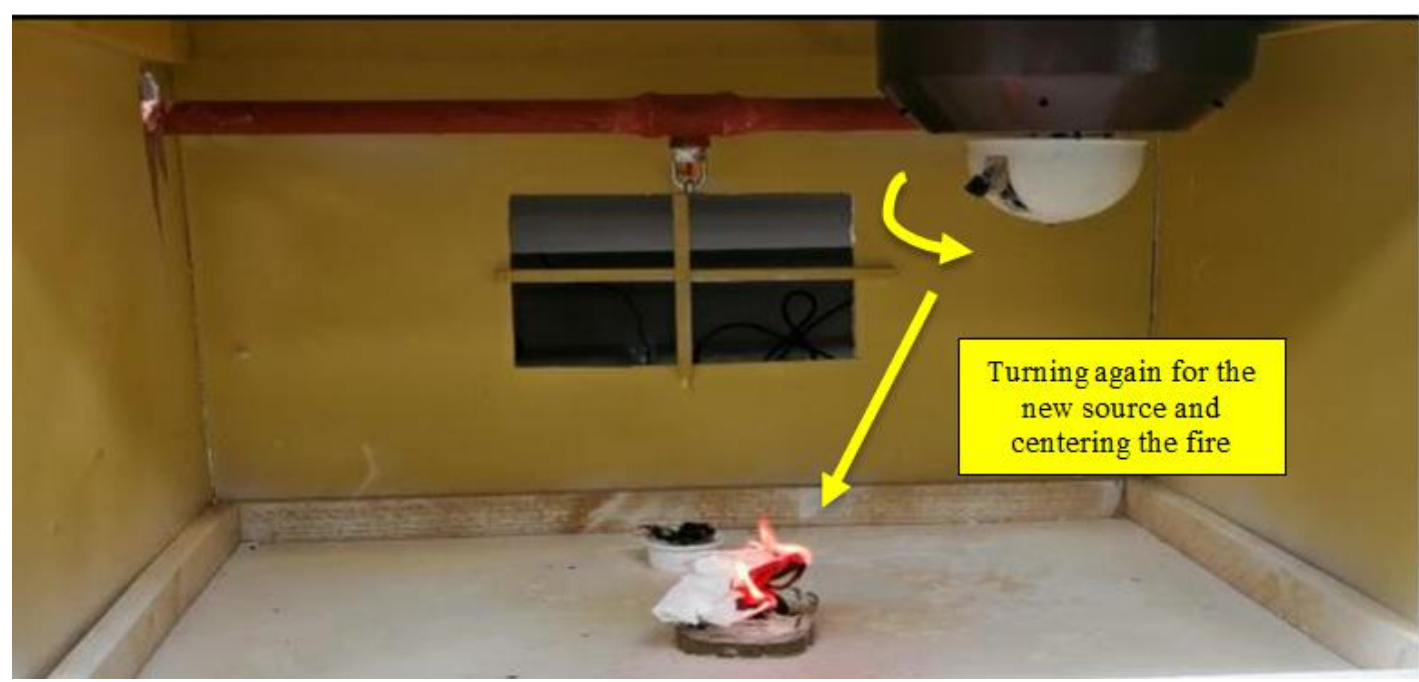

Figure 11. A view of a third examine of the fire inside the room

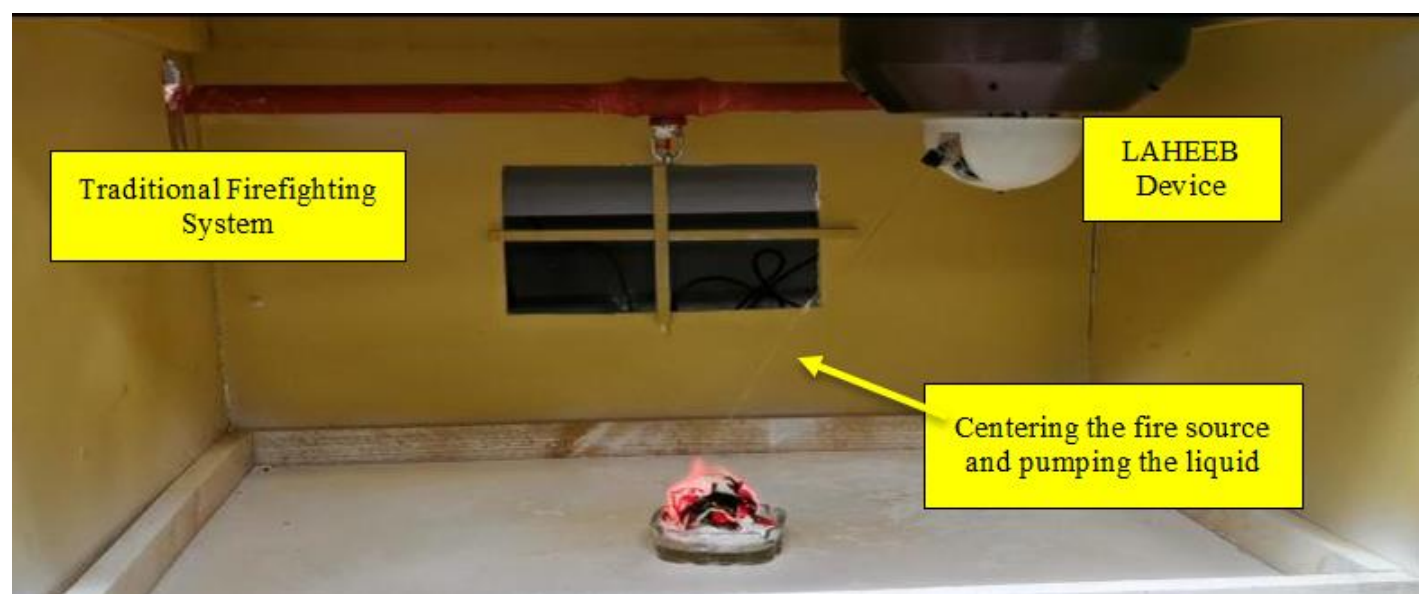

Figure 12. The device pumping the liquid to the fire source through sprayer 


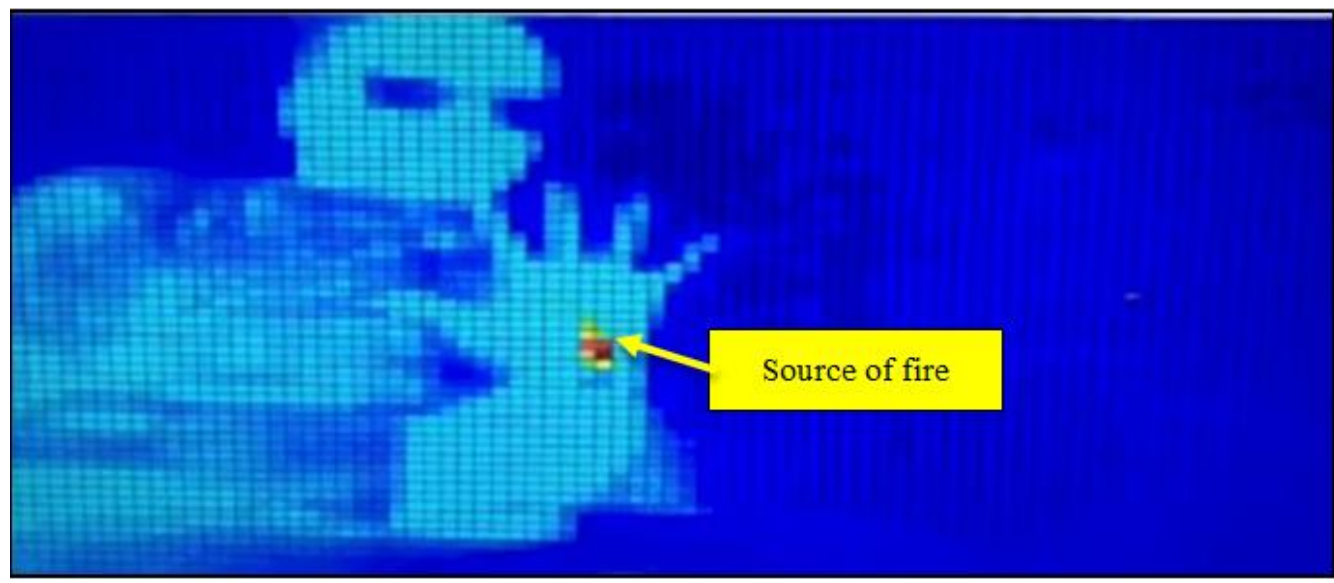

Figure 13. Testing the thermal camera results by using Matlab

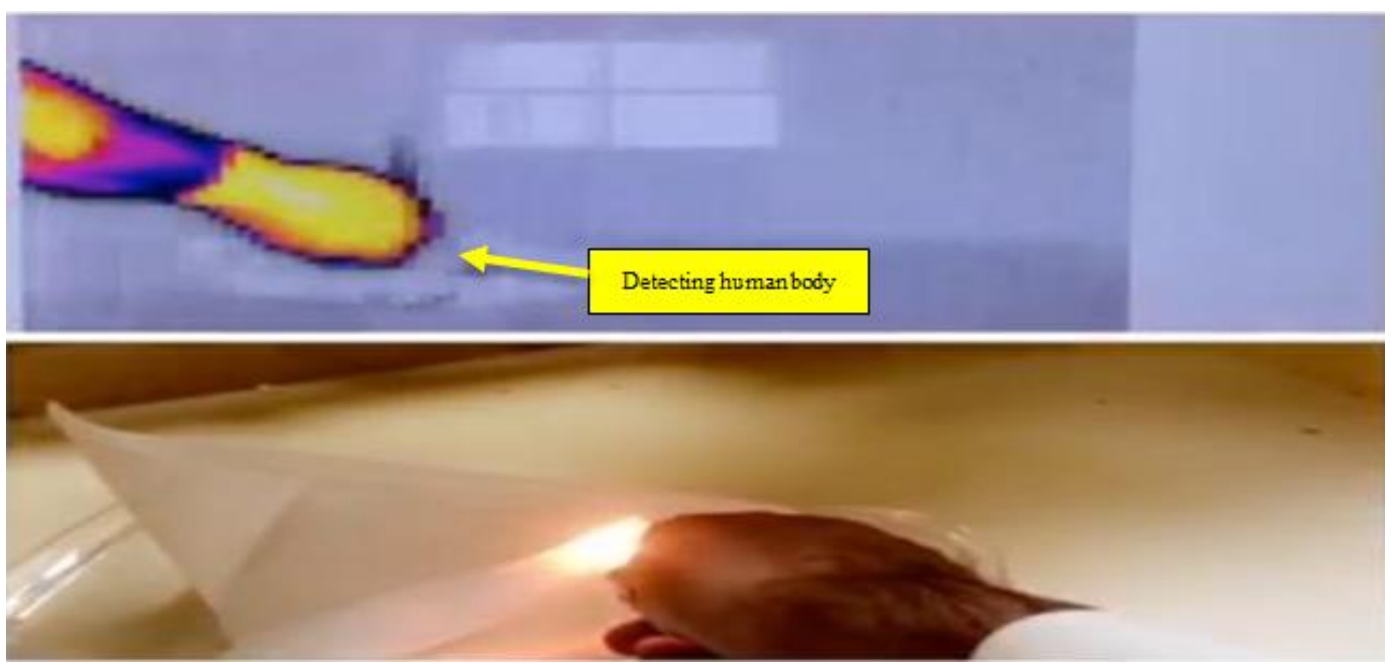

Figure 14. Thermal camera test of detecting the surface of the human and the source of fire
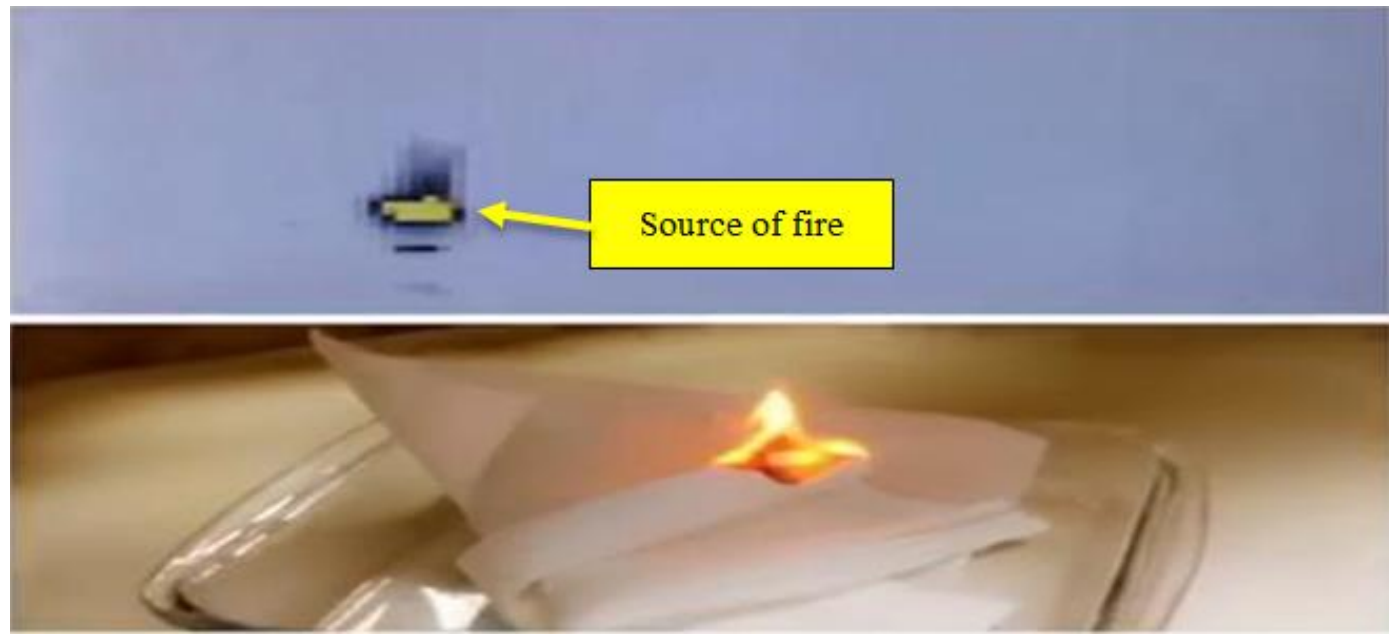

Figure 15. Thermal camera test of detecting the source of fire and human hand 

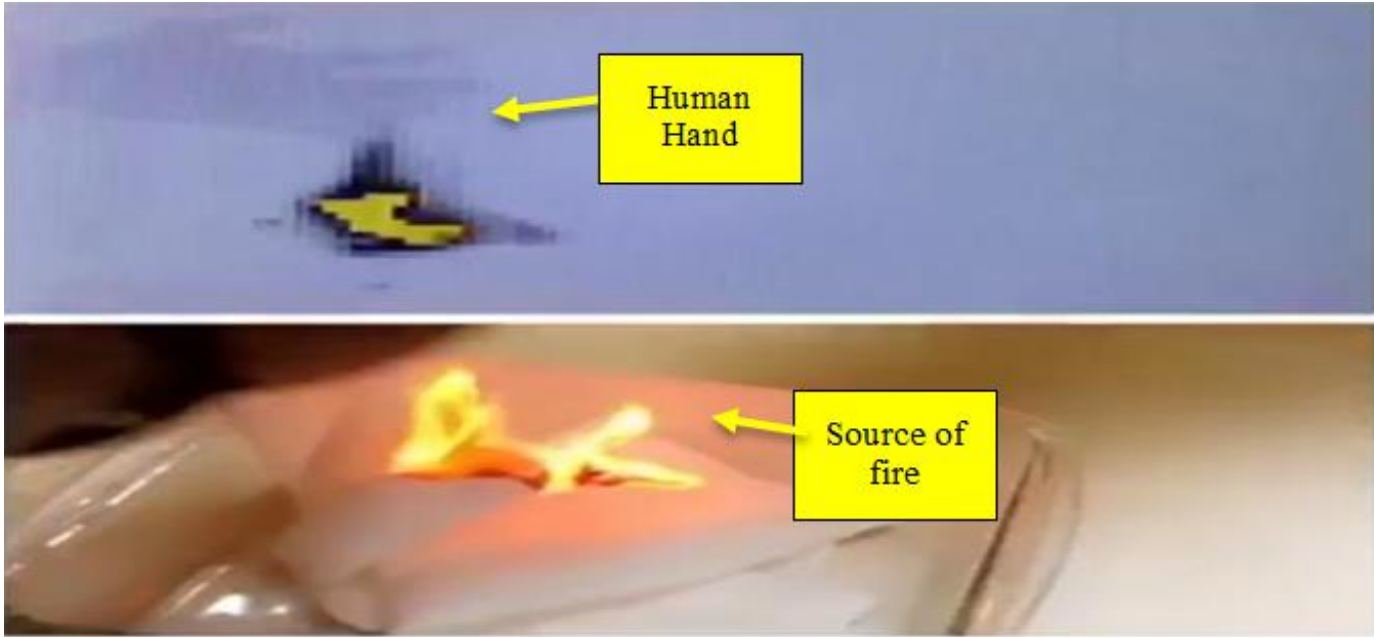

Figure 16. Thermal camera test of detecting the source of fire and human hand

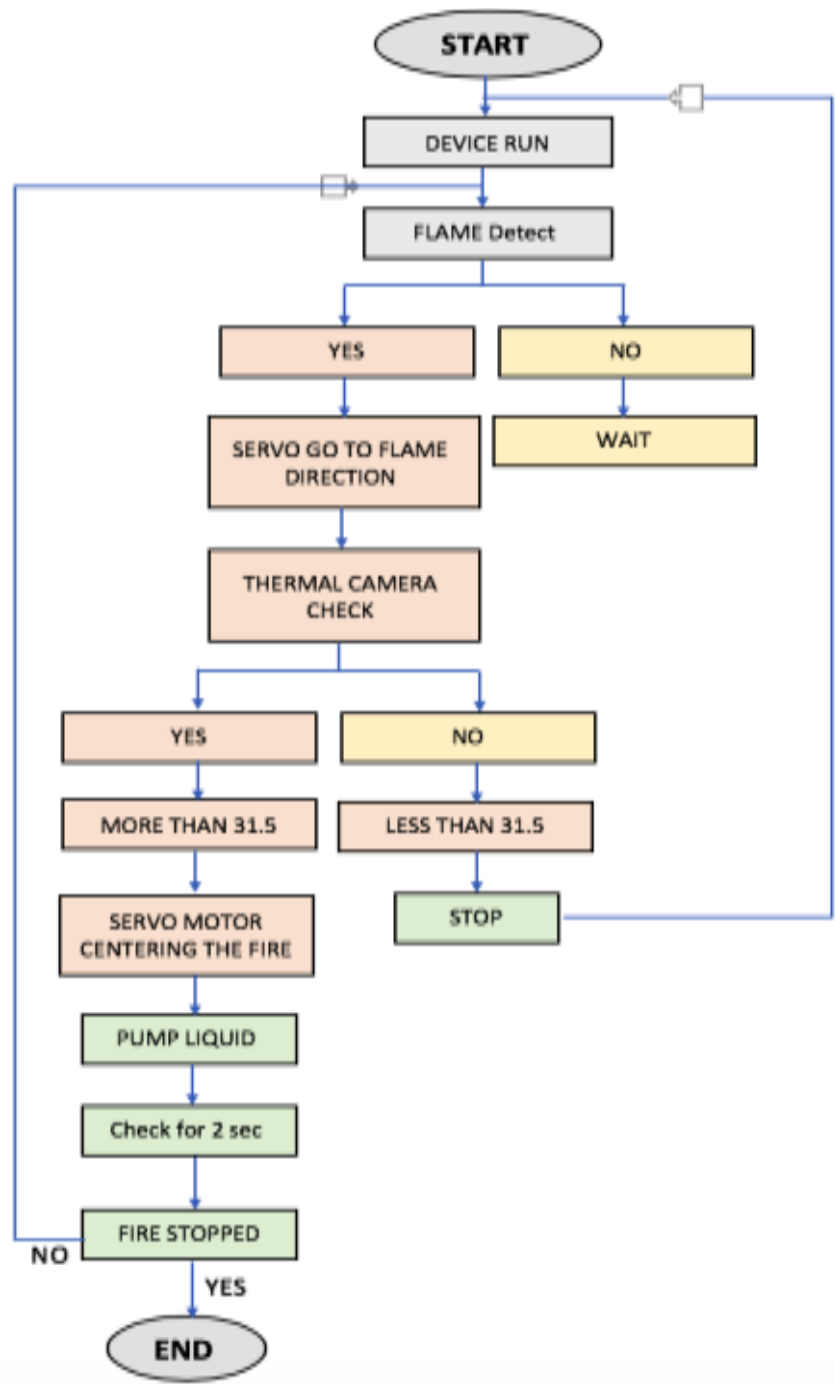

Figure 17. Flowchart of smart firefighting device system (LAHEEB) 


\section{CONCLUSION}

In the present work, the designing and testing of a smart firefighting device system (LAHEEB) had been discussed. The above device is designed to detect the source of fire, extinguish it, and increase the knowledge about fire behavior from incident area. From the experimental results, a smart fire-fighting device (LAHEEB) has achieved its aim and objective successfully. The device developed to help firefighters in their duty. It has advantageous features such as the ability to detect the source of fire, extinguish it and increase the knowledge about fire behavior from the incident area. LAHEEB can extinguish different types of fire $\mathrm{A}, \mathrm{B}, \mathrm{C}, \mathrm{D}, \mathrm{F} / \mathrm{K}$, electric and metal fire without spreading in the shortest time. This robot will reduce the risk of injury for firefighters and possible victims and decrease the monetary losses which increase considerably as fire duration increases. LAHEEB also can avoid hitting obstacles or surrounding objects by using sensors.

\section{REFERENCES}

[1] RobotShop Distribution Inc. History of Robotics: Timeline, 2008.

[2] F. Tanaka, et al., "Telepresence robot helps children in communicating with teachers who speak a different language," in Proceedings of the 2014 ACM/IEEE international conference on Human-robot interaction, Bielefeld, Germany, 2014, pp. 399-406.

[3] E. H. Harik and A. Korsaeth, "Combining Hector SLAM and Artificial Potential Field for Autonomous Navigation Inside a Greenhouse," Robotics, vol. 7, no. 2, pp. 22, 2018

[4] H. Singh, "Design and Development of an Autonomous Robot," 2019.

[5] J. Lee, et al., "Industrial robot calibration method using denavit-Hatenberg parameters," in 17th International Conference on Control, Automation and Systems (ICCAS), 2017, pp. 1834-1837.

[6] S. Jeelani, et al., "Robotics and medicine: A scientific rainbow in hospital," Journal of Pharmacy \& Bioallied Sciences, vol. 7, no. Suppl 2, pp. S381-S383, 2015.

[7] M. Yusof and T. Dodd, "Pangolin: A Variable Geometry Tracked Vehicle with Independent Track Control," Field Robotics, pp. 917-924, 2017.

[8] C. Xin, et al., "Design and Implementation of Debris Search and Rescue Robot System Based on Internet of Things," in International Conference on Smart Grid and Electrical Automation (ICSGEA), pp. 303-307, 2018.

[9] C.-P. Day, "Robotics in Industry-Their Role in Intelligent Manufacturing," Engineering, vol. 4, no. 4, pp. 440-445, 2018.

[10] M. Aliff, S. Dohta, and T. Akagi, "Simple Trajectory Control Method of Robot Arm Using Flexible Pneumatic Cylinders," Journal of Robotics and Mechatronics, vol. 27, no. 6, pp. 698-705, 2015.

[11] M. Aliff, S. Dohta, and T. Akagi, "Control and analysis of simple-structured robot arm using flexible pneumatic cylinders," International Journal of Advanced and Applied Sciences, vol. 4, no. 12, pp. 151-157, 2017.

[12] M. Aliff, S. Dohta, and T. Akagi, "Control and analysis of robot arm using flexible pneumatic cylinder," Mechanical Engineering Journal, vol. 1, no. 5, pp. DR0051-DR0051, 2014.

[13] A. Dhumatkar, et al., "Automatic Fire Fighting Robot," International Journal of Recent Research in Mathematics Computer Science and Information Technology, 2015.

[14] Y. Samkari, et al., "A Smart Firefighting Robot System (LAHEEB)," International Journal of Engineering and Technology, vol. 11, pp. 359-366, 2019, 10.21817/ijet/2019/v11i2/191102065.

[15] J.D. Setiawan, M. Subchan, A. Budiyono, "Virtual Reality Simulation of Fire Fighting Robot Dynamic and Motion," in ICIUS, October 24-26, 2007.

[16] C. Flesher, et al., "Fire Protection Robot Final Report," pp. 1-78, 2004.

[17] M. Durkin, et al., "Firefighting Robot: A Proposal," May 5, 2008.

[18] G. Weed, et al., "Pokey the Fire-Fighting Robot-A Logical Design Using Digital and Analog Circuitry," 1999.

[19] J.-H. Kim, S. Jo, and B.Y. Lattimer, "Feature Selection for Intelligent Firefighting Robot Classification of Fire, Smoke, and Thermal Reflections Using Thermal Infrared Images," Journal of Sensors, pp. 13, 2016.

[20] R. N. Haksar and M. Schwager, "Distributed Deep Reinforcement Learning for Fighting Forest Fires with a Network of Aerial Robots," in IEEE/RSJ International Conference on Intelligent Robots and Systems (IROS), pp. 1067-1074, 2018.

[21] S. Jiang, et al., "Buckling Behaviour of Aluminium Alloy Columns under Fire Conditions," Thin-Walled Structures, vol. 124, pp. 523-537, 2018, doi:10.1016/j.tws, 2017.12.035.

[22] M. Aliff, et al. "Development of Fire Fighting Robot (QRob)," International Journal of Advanced Computer Science and Applications, vol. 10, no. 1, 2019, doi:10.14569/ijacsa.2019.0100118.

[23] A. M. A. Ghiet and A. Baba, "Robot Arm Control with Arduino," 2017, doi: 10.13140/RG.2.2.10227.53286.

[24] M. S. Nagesh, et al. "Fire Extinguishing Robot," Ijarcce, vol. 5, no. 12, pp. 200-202, 2016, doi:10.17148/ijarcce.2016.51244

[25] M. Rajesvari, et al., "Autonomous Fire Fighting Robot with Multi Sensor Fire Detection Using Arduino," in National Conference on Emerging Technologies for Sustainable Engineering \& Management (NCETSEM'18), 2018.

[26] Arduino DUE, www://store.arduino.cc/usa/due, 2019.

[27] S. Ferdoush, X. Li, "Wireless sensor network system design using Raspberry Pi and Arduino for environmental monitoring applications," Procedia Computer Science, vol. 34, pp. 103-110, 2014. 


\section{BIOGRAPHIES OF AUTHORS}

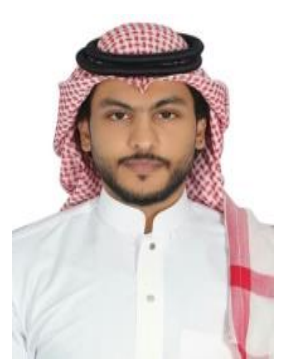

Yousef Samkari received his bachelor's degree in Electrical Engineering from Gannon University in 2015 and his master's degree in Mechanical Engineering from Umm Al-Qura University in 2019. He worked in the department of engineering, where he was responsible for research projects in the area of robotics.

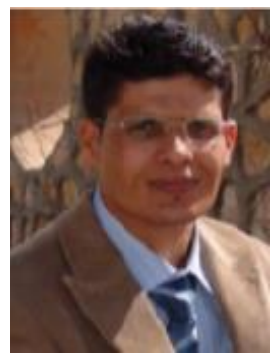

Kamel Guedri received his bachelor's, master's, and $\mathrm{PhD}$ degree in Energy Engineering $\mathrm{He}$ worked as a consular of Umm Al-Qura University (UQU) for the branches. Then he worked as the Director of Mechanical Engineering.

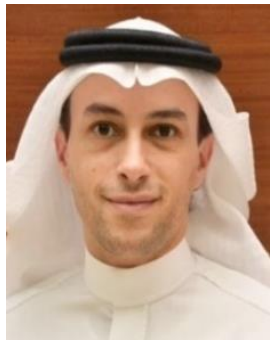

Mowffaq Oreijah received his master's degree from the University of Melbourne in 2009 and his PhD from the RMIT University in 2015. He worked as assistant professor in the department of mechanical engineering and had assigned as the Chairman of Mechanical Engineering, Umm Alqura University (UQU) for two years. Then he worked as the Director of Intellectual Property in Umm Alqura University (UQU) and Dean of Institute of Entrepreneurship and Innovation.

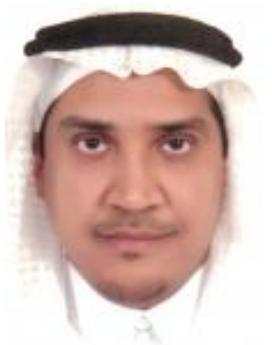

Shadi Munshi received his Ph.D. in Mechanical/Mechatronic Engineering with fifteen years of academic experience in Sydney-Australia and Makkah-Saudi Arabia. Specialized in Mechatronic and Mechanical Engineering, Designing and Modelling.

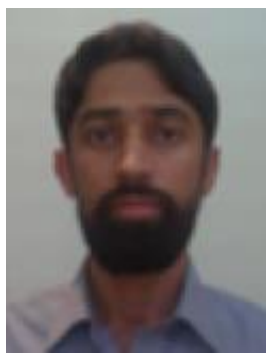

Sufyan Azam received his Mechanical/Mechatronic Engineering - Sensors, MEMS, Nano Composite Materials, Design, Vibration, Rapid Prototyping and Reverse Engineering. 